\title{
Semantically Enhanced Historical Cartoons Promoting Historical Interpretation
}

\author{
Daiki Muroya*, Kazuhisa Seta* and Yuki Hayashi*
}

(Received 12 August 2020 and accepted in revised form 8 February 2021)

\begin{abstract}
The importance of cultivating learning attitudes that enable learners to not only memorize key facts but also gain insights into the background of these facts is widely recognized. This study aims to develop a novel learning support system that imparts a positive learning attitude to learners by having them perform historical interpretation activities in an exploratory manner by using historical cartoons that illustrate historical events as learning materials. This study proposes a historical interpretation activity support system based on cartoon semantics whereby learners can perform self-exploratory learning in a step-by-step manner according to the historical interpretation process model. The proposed system also aims to provide them with support to encourage their historical interpretation activity according to their interests and learning situations. It was confirmed that the proposed system helps to promote the learners' interpretation of history instead of rote learning and has the potential to change their learning attitude toward history.
\end{abstract}

Keywords historical cartoon semantics, historical interpretation, question generation ontology

\section{Introduction}

It is important for learners to perform interpretation activities from their own original viewpoints. This not only deepens their knowledge but also helps to cultivate their logical thinking skills by viewing topics from different angles.

In particular, it is recognized that historical consid-

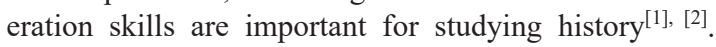
Historical consideration is a knowledge-building activity whereby learners develop their own historical interpretations of historical events by thoroughly investigating the circumstances surrounding the events. For example, consider the interpretation of Japan's victory in the Sino-Japanese War that triggered the advance of Western powers into the Qing dynasty and opened the door to the imperialist era. Studying such an interpretation requires a learning attitude whereby learners have access to an extensive range of knowledge about historical facts and causal relations. However, ordinary learners find it difficult to identify historical viewpoints that can be used to interpret a historical event (e.g., viewpoints about national strategies from which one can interpret historical events), and often fall back on rote learning of historical facts ${ }^{[3]}$.

Shindo conducted a questionnaire survey of 159

\footnotetext{
* Graduate School of Humanities and Sustainable System Sciences, Osaka Prefecture University, Japan
}

university students to clarify the relationships between their learning strategies and motivation to learn history and found that students who used deeper learning strategies such as historical consideration tended to learn in a self-directed and self-exploratory way with higher motivation $^{[4]}$.

It has also been pointed out that self-directed and self-exploratory learning requires enhanced inquirybased internal self-conversation. Ciardiello showed that a learner's ability to question oneself is the most useful cognitive activity in various learning scenarios because it enhances one's ability to search for an original answer $^{[5]}$.

Yoshikawa proposed a spiral model to explain the generation of inquiries, the transitions of these inquiries in individual learners and learner groups, and the resulting direction of exploratory learning processes in history education ${ }^{[6]}$. Based on this model, this study built a learning environment wherein learners are prompted to study historical contexts in greater depth by generating their own inquires ${ }^{[7]-[9]}$.

In this study, "historical cartoons" are focused on as learning materials to prompt self-directed exploratory learning among students to assist them to gain a deep understanding of historical events. This study aims to build a learning environment that uses semantically enhanced historical cartoons to cultivate learning attitudes whereby learners try to understand the background of historical events more deeply and are 
prompted to develop their own original historical interpretations. This paper is an extension of the work originally reported in [7], [8], and [9].

\section{Prompting Historical Interpretation Activities via Historical Cartoons}

\subsection{The Use of Historical Cartoons to Motivate Learning}

It is known that the use of cartoons as learning materials can diminish boredom and enhance the learners' motivation and interest. Takahashi et al. ${ }^{[10]}$ indicated that learners can discover new viewpoints of learning by discerning a large amount of information naturally embedded in a cartoon. This is one of the characteristics of cartoons used as learning materials.

In this paper, the term "historical cartoon" means a single page painting source, which includes strong messages conveyed by the cartoonist having a point of view. Such a cartoonist conveys information about the state and behavior of characters in a historical event by imagining what they might be thinking. They are known as "Fushiga" in Japanese.

Miyahara argued in [11] that the meaningfulness of using painting sources of history lies in their ability to ensure learners' engagement in classes. Ikeno emphasized the importance of having a viewpoint of historical events to deepen one's understanding regarding these events. He revealed how using painting sources facilitates learners' active historical understanding by contributing to the determination of their viewpoints ${ }^{[12]}$.

Aoki, a practitioner of history education, who continues using historical cartoons (Fushiga), pointed out that historical cartoons reflect and offer the cartoonists' viewpoints; thus, learners also discern these viewpoints while interpreting the message of historical cartoons by referring to Ikeno's argument. Furthermore, he pointed out that the viewpoint of the historical cartoon is located in a place where it is easier to find than general painting historical materials. Using historical cartoons in history instruction positively affects the learners' history learning related to the determination of their viewpoint ${ }^{[13]}$.

Therefore, the use of historical cartoons as learning materials offers a promising way to encourage learners to move away from rote learning of facts and toward a more investigative and interpretive learning style in which they start by interpreting the cartoonist's inten- tions and interpretations, thus becoming able to investigate the causal relations and background circumstances that led to that particular situation. There have been efforts to build libraries of historical cartoons (including Fushiga) for history learning around the world, for example, the History Teaching Institute at the Ohio State University offers a portal site for the provision of historical cartoons for history education ${ }^{[14]}$. However, these cartoons are not machine-understandable. Thus, this study aims to propose a three-layered historical cartoon semantics model (described later in Section 3) to make these cartoons machine-understandable. This will realize learning support by the computer system to learners to gain the abovementioned learning benefits of using historical cartoons for history learning.

Fig. 1 presents an overview of this research. Historical cartoons are used in this study to convey the cartoonists' interpretations of historical events from different viewpoints. These cartoons are used as learning materials in this study to enhance the learners' historical interpretation abilities.

\subsection{Learning Process Design of Historical Interpretation}

To prompt historical interpretation activities using historical cartoons, it is important to take into account that ordinary learners do not have the same facilities as history researchers with regard to assessing and interpreting historical documents. Therefore, there is a need to provide these learners with adequate support for their self-directed reading of historical cartoons. In this research, the learning activities shown in Table 1 were designed by referring to three strategies ${ }^{[15]}$ that historians use when reading historical artworks.

\subsection{Types of Questions that Prompt Historical Interpretation}

Many studies have demonstrated the usefulness of posing questions to learners. In the context of supporting history learning, it is also well known that posing questions can help to deepen the learners' historical understanding.

Counsell classified questions that prompt understanding of history into four types ${ }^{[16]}$ : (i) descriptive questions, (ii) causal questions, (iii) comparison questions, and (iv) evaluative questions. 


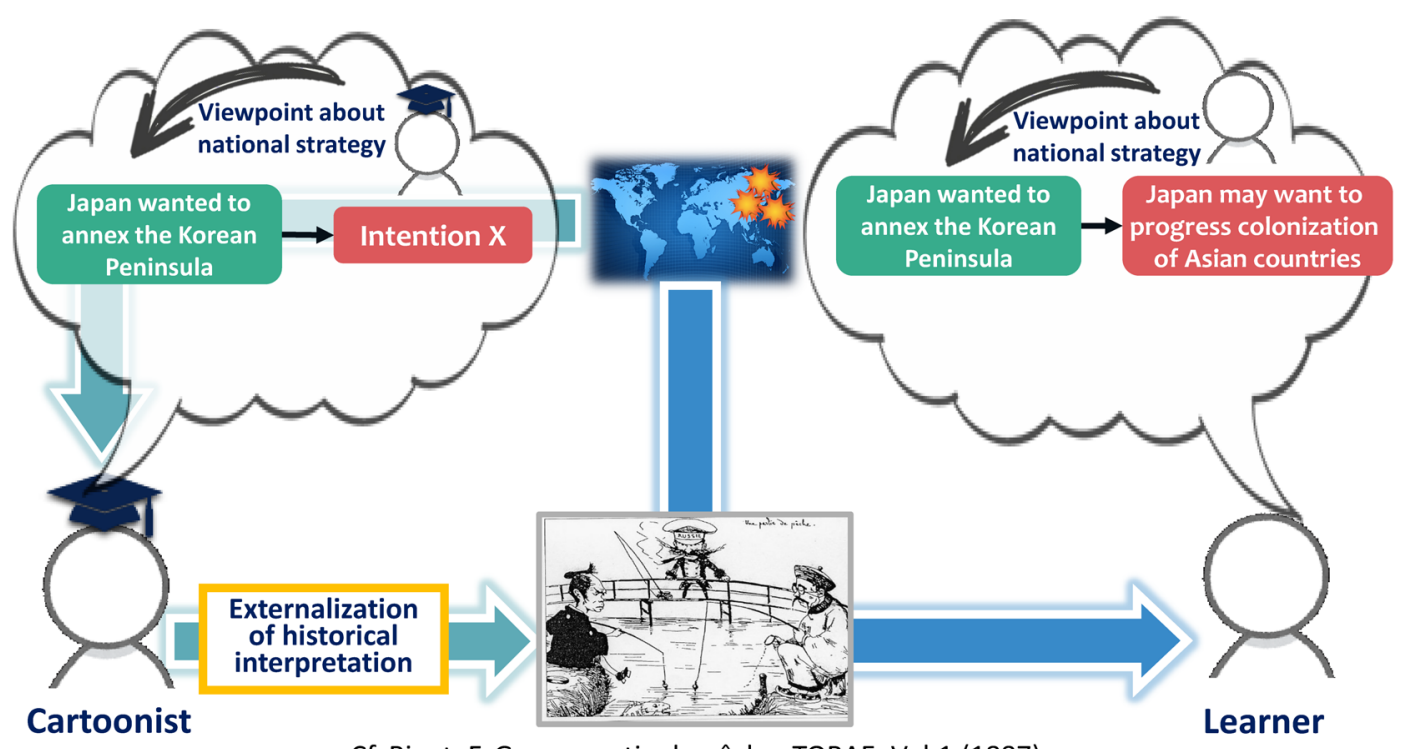

Cf. Bigot, F. G. une partie de pêche. TOBAE, Vol.1 (1887)

Figure 1. Overview of the research

Table 1. Historical interpretation process via historical cartoons

\begin{tabular}{l|l}
\hline \multicolumn{1}{c|}{ Learning Process } & \multicolumn{1}{c}{ Learning Activities } \\
\hline (i) Read overall components and their relations. & Observe and read the states and behaviors of each object. \\
\hline (ii) Analyze facts. & $\begin{array}{l}\text { (a) Consider what each object represents. } \\
\text { (b) Consider each object as a representation of a historical background or an } \\
\text { expression of some historical viewpoint, for example, respective national } \\
\text { strategies. }\end{array}$ \\
\hline (iii) Build own interpretation. & $\begin{array}{l}\text { Consider the effects of the object on subsequent historical movements by inter- } \\
\text { preting and integrating historical backgrounds and thoughts from various } \\
\text { viewpoints based on the results of (ii) (b). }\end{array}$ \\
\hline
\end{tabular}

Additionally, in historical interpretation activities wherein it is not possible to specify clear and unique answers, learners have to conduct self-directed inference activities. After an investigation was conducted by van Dire et al. to determine what sort of questions contribute to cultivating the inference activities of learners in the history domain, they indicated that evaluative questions are the most effective in this regard ${ }^{[17]}$.

\section{Historical Interpretation Activity Support System}

\subsection{Requirements}

It is important that learners do not regard the historical interpretations provided by teachers as indisputable facts that must be committed to memory without question. Rather, they should seek to deepen their own understanding and construct their own interpretations in a self-exploratory way. However, it is difficult for learners to accomplish this without adequate support for self- 


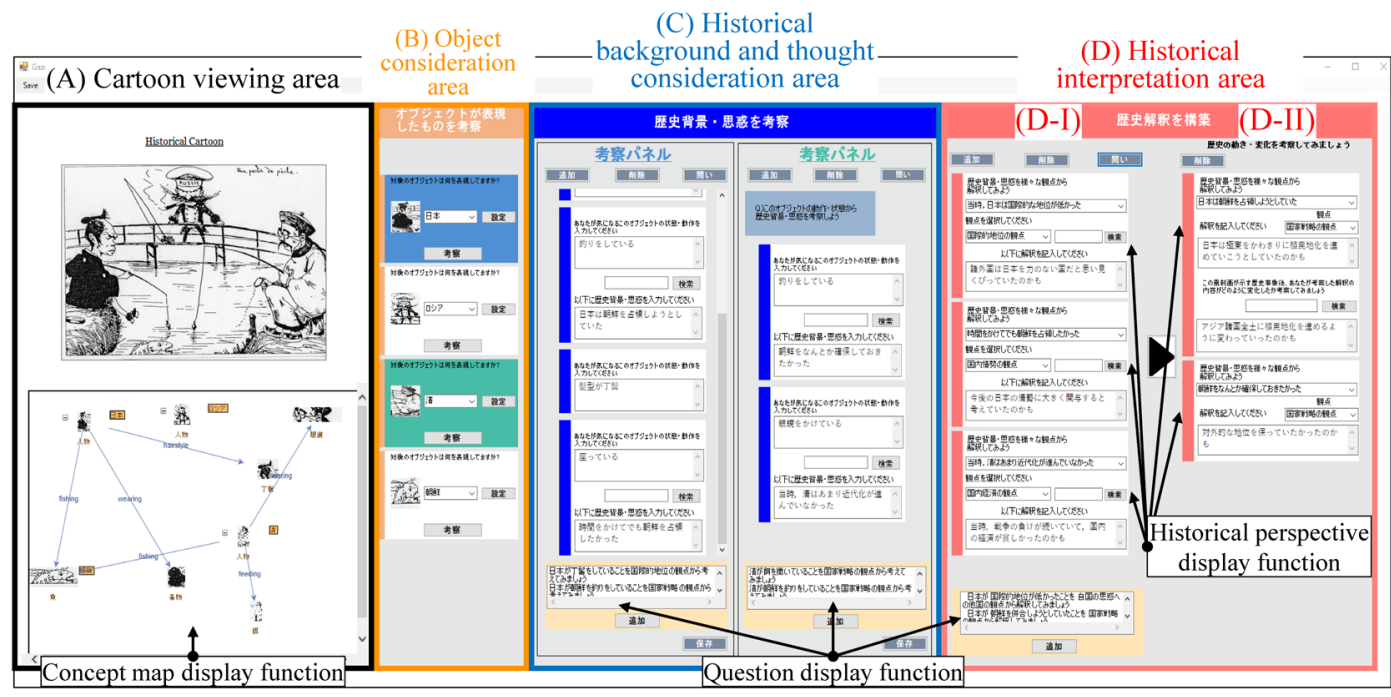

Figure 2. System interface

directed learning. Therefore, the computer system must provide adaptive support to learners to help them overcome this hurdle. In this research, the authors of this study try to satisfy the following two requirements as well as to adopt historical cartoons as learning materials. - Learners become able to perform self-exploratory learning in a step-by-step manner according to the historical interpretation process model shown in Table 1.

- Learners are provided with support to encourage their historical interpretation activities according to their interests and learning situations.

\subsection{Learning Support System for Historical Interpretation}

The authors of this study developed a learning support system for historical interpretation activities that satisfied the above two requirements. This system uses a server-client architecture with a database (DB) server called Virtuoso Open Server and client systems implemented in the $\mathrm{C \#}$ programming language. The client systems can capture the learner's eye movements as well as keyboard and mouse operations, and save both the eye movements and these operations as learning log files in a comma separated value (CSV) format.

Fig. 2 shows the interface of the proposed system. The system is designed so that learners can perform his- torical interpretation activities and then build their own original historical interpretations according to the model shown in Table 1. It comprises the following four areas: (A) cartoon viewing area, (B) object consideration area, (C) historical background and thought consideration area, and (D) historical interpretation area. In this interface, learners start their historical interpretation activity from area (A) and then gradually build their own historical interpretations in a step-by-step manner from (B) to (D). The details of each area are described below.

A. Cartoon viewing area: This area shows a historical cartoon as a learning resource and concept map. The learners examine each object depicted in the cartoon and take notes on their states and behaviors; for example, this man is wearing a kimono, the man on the bridge is watching them trying to fish, etc.

When it is detected that the learner's gaze is fixated on a particular object in the cartoon, the system shows a pop-up window that prompts the learner to think more deeply about the object. Subsequently, the representation object that the learner tries to think about deeply is magnified with more details when the learner gazes at it. The object is also located and visualized in a concept map at the bottom. This is called the "concept map display function." Currently, the areas of interest (AOIs) are attached to the char- 
Table 2. Knowledge layers for the specification of historical cartoon semantics

\begin{tabular}{ll}
\hline \multicolumn{1}{c}{ Knowledge Layer } & \multicolumn{1}{c}{ Knowledge Specified } \\
\hline (I) Presentation & Specify the relevant objects and their behavior and state. They are read in the learning phase (i). \\
\hline (II) Historical Structure & $\begin{array}{l}\text { Specify the historical background and thoughts regarding the relevant objects. They are considered } \\
\text { in the learning phase (ii). }\end{array}$ \\
\hline (III) Historical Viewpoint & $\begin{array}{l}\text { Specify the historical viewpoint. It plays a fundamental role in historical interpretation in the learn- } \\
\text { ing phase (iii). }\end{array}$ \\
\hline
\end{tabular}

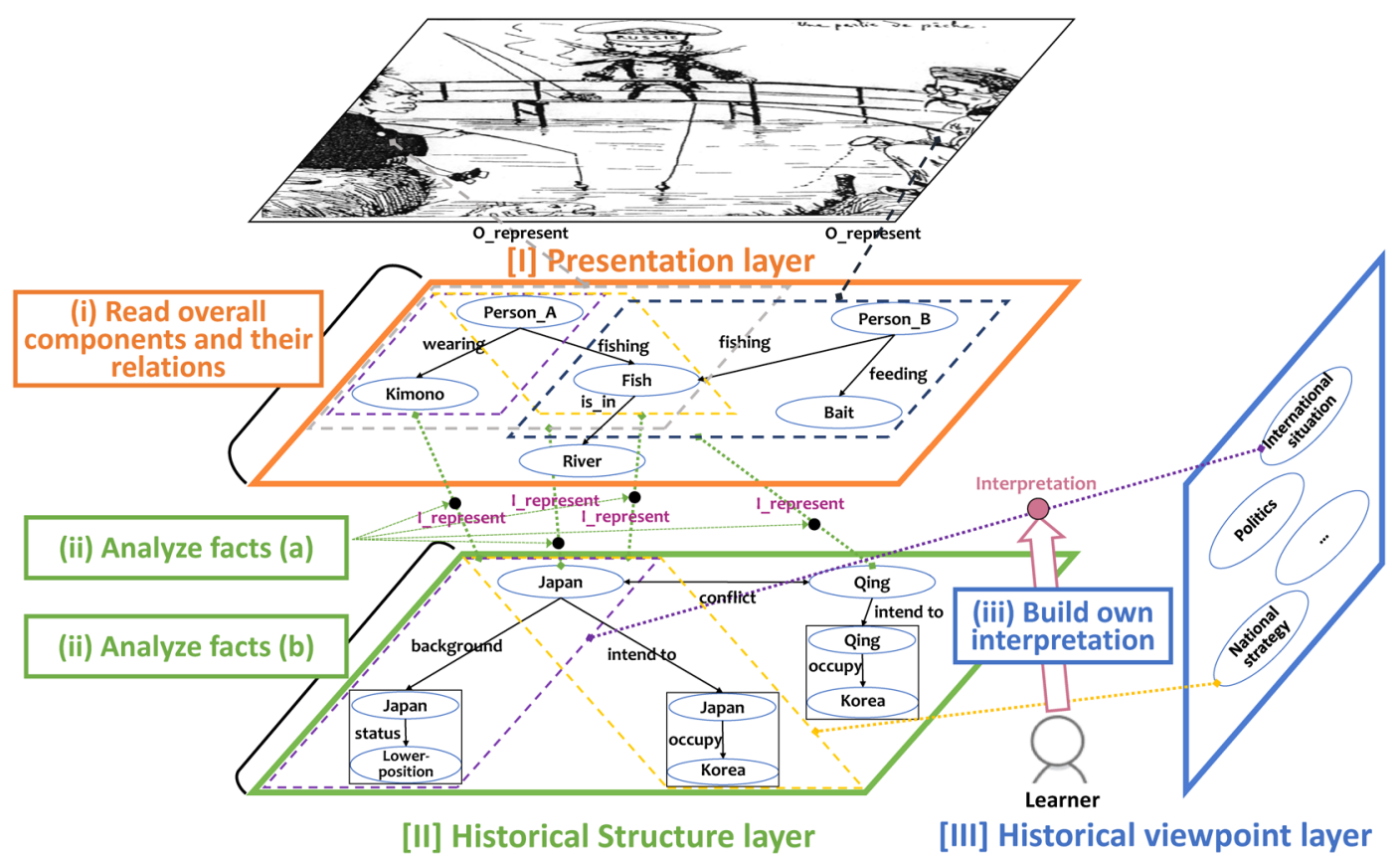

Figure 3. Historical cartoon semantics model

acters and their states and behaviors in the historical cartoon in order to capture the learners' eye movements on the representation objects.

B. Object consideration area: This area is provided for learners to consider each object and the stakeholder it represents (e.g., a nation or organization). The learner associates stakeholders with each object by choosing from a list defined by the authors of the learning materials, that is, the authors of this study.

The system judges whether the results are adequate and offers suggestions to learners to reconsider based on the historical cartoon semantics of the learning materials.

\section{Historical background and thought consideration}

area: This area is provided for the learners to consider the historical background and the respective stakeholders' thoughts by observing their states or behaviors. It consists of two panels in which the learners can deepen their thinking about the historical background and the thoughts of the stakeholders of the objects they wish to consider. By providing multiple panels, the system aims to encourage learners to make comparisons between different objects.

The system includes historical cartoon semantics (described in Section 3.3) that convey historical background and thoughts (Fig. 3[II]) and historical viewpoints (Fig. 3[III]) with AOIs regarding the corresponding representation objects. Based on the his- 
torical cartoon semantics and question generation framework, this area displays questions that encourage the learner to consider historical backgrounds and thoughts according to the learner's request; for example, "Let us consider from an international status viewpoint why the Japanese man is depicted with a topknot hairstyle?" We call this function the "question display function." This area also features a web browser with a search engine that uses Google Custom Search API to support historical queries.

D. Historical interpretation area: In this area, the learners build their original historical interpretations and historical movements by considering the historical background and thoughts gathered in area (C). The learners indicate their thoughts about the historical event, then either choose a pre-prepared historical viewpoint or create their own interpretation of the historical background. Their historical viewpoint is based on the specifications of the historical cartoon semantics (Fig. 3[III]). This is called the "historical perspective display function." The learners build their original historical interpretation in Fig. 2 (D-I) by deepening their thoughts regarding historical events based on the set of historical viewpoints.

When requested, the system asks questions to prompt learners to undertake further historical interpretation with the same mechanism that is employed in area (C) (e.g., Let us consider why Japan wanted to annex the Korean Peninsula by force based on the viewpoint of Japan's domestic economy). It also provides a search function. When the learner clicks the arrow button, the statement described moves on to area D-II, where the learner can deepen their contemplation regarding the historical event by thinking about its significance and impact on subsequent eras.

\subsection{Historical Cartoon Semantics and Adaptive Support}

The content of historical cartoons needs to be presented in a way that can be machine-understandable to implement adaptive support mechanisms that can help learners to grasp the content of a learning context.

The authors of this research propose the three-layered historical semantics model shown in Fig. 3, which corresponds to the historical interpretation process model (shown in Table 1) as the basis of the proposed historical cartoon learning support system. This model comprises presentation, historical structure, and historical viewpoint layers, and provides adaptive support to learners by capturing their process in the historical interpretation model. Table 2 presents the details of each layer.

Furthermore, in general, it is difficult for the system to provide appropriate adaptive support by capturing learners' thinking processes according to their interests since these thinking processes are tacit and latent. In this research, the system (1) focuses on interactions through gaze recognition and semantically enhanced representation objects to capture the learners' interests, and (2) provides adaptive questions based on the historical cartoon semantics-based question generation mechanism according to the learners' learning processes.

Regarding (1), by specifying a gaze-aware representation object at the presentation layer, the system can capture part of a learner's interests from their eye movements on the cartoon, allowing the system to interact with the learner based on the semantics attached to the target representation object.

Regarding (2), by specifying computational semantics according to the historical cartoon semantics model, the system can generate semantics-based questions by using the question generation framework developed in the previous work of the authors of this study ${ }^{[18],[19]}$. Specifically, the system can provide support for historical interpretation activities by giving "evaluative questions" that prompt the learners' inference activities.

On the other hand, one of the things most learners find difficult to understand is the intention of their instructor when giving evaluative questions, because evaluative questions tend to appear ambiguous to learners who cannot understand the intent of the questions and how they have to think to answer such questions properly ${ }^{[20]}$.

To overcome this problem, the system provides evaluative questions with "historical viewpoints" to be considered, for example, asking learners to consider why Japan intended to occupy China (at the time, China was under the rule of the Qing dynasty) as part of its national strategy, based on the historical semantics specified at the historical structure and historical viewpoint layers.

These questions are generated based on the historical cartoon semantics (knowledge base) and the evaluative question template specified in the question generation ontology. By developing the question generation 
Table 3. Knowledge layers for the specification of historical cartoon semantics

\begin{tabular}{ll}
\hline \multicolumn{1}{c}{ Duration } & \multicolumn{1}{c}{ Details } \\
\hline Learning awareness & $\begin{array}{l}\text { History learning awareness questionnaire } \\
\text { Learning about the Sino-Japanese War } \\
\text { Comprehension quiz (10 questions) }\end{array}$ \\
\hline $40 \mathrm{~min}$ & $\begin{array}{l}\text { Historical consideration of the Sino-Japanese War } \\
\text { (report writing) }\end{array}$ \\
\hline $15 \mathrm{~min}$ & $\begin{array}{l}\text { Description of historical interpretation using cartoons } \\
\text { Description of system operation and learning activities }\end{array}$ \\
\hline $10 \mathrm{~min}$ & $\begin{array}{l}\text { Practicing of using the system (learning materials: cartoons depicting the first House of Representatives } \\
\text { election) }\end{array}$ \\
\hline $45 \mathrm{~min}$ & Break \\
\hline $20 \mathrm{~min}$ & $\begin{array}{l}\text { Using the system to learn about the historical interpretations of the Sino-Japanese War (learning materials: } \\
\text { cartoons depicting the situation just before the war started) }\end{array}$ \\
\hline $10 \mathrm{~min}$ & Review of historical study themes (modification of report) \\
\hline
\end{tabular}

framework, the system can dynamically generate questions that encourage interpretation activities for various historical cartoons by adding or modifying historical cartoon semantics without having to specify different questions for each historical cartoon.

\section{System Use and Usefulness Evaluation}

\subsection{Evaluation Aims and Procedure}

User evaluation trials were conducted in this study to confirm whether the proposed system can encourage learners to engage in exploratory history interpretation activities and provide a mechanism that can cultivate a learning attitude that induces learners to become willing to find out about the backgrounds of and connections between history topics. Table 3 shows the system use flowchart and the task details. Based on the results of a preliminary survey on historical learning awareness ${ }^{[21]}$, the authors of this study selected 16 undergraduate and graduate students to participate in the study and divided them into two groups of eight people (experimental groups 1 and 2). The divided groups had no bias in learning awareness. Each group used the history interpretation support system based on the learning design described in Section 2.2, and the eight members of experimental group 2 used the system with added adaptive support functions (question display function, histor- ical perspective display function, and concept map display function).

Additionally, since all learners are assumed to have some amount of basic knowledge on the subject they are learning about, the students were asked to conduct preparatory studies on the First Sino-Japanese War (18941895) and to complete a quiz containing 10 questions on the subject (roughly high school level questions). Consequently, it was confirmed that all 16 learners had acquired basic knowledge on this subject (average score: 8.5 ).

\subsection{Analysis Results}

Transformation of History Learning Awareness. The system's effects on history learning awareness of students were investigated by having them complete a questionnaire on history learning awareness ${ }^{[21]}$ before and after using the system. The results are shown in Fig. 4.

Experimental groups 1 and 2 both showed a tendency of positive transformation in their impressions of history learning (items: (1) Motivation for studying history and (2) Impression of fun). Additionally, neither group showed negative transformations in their impressions of rote learning (items: (3) Impression of rote learning, (4) Emphasis on rote learning, and (5) Rote learning strategy), together with increased awareness of strategies for connected understanding (items: (6) Impression of connections, (7) Emphasis on connection, 


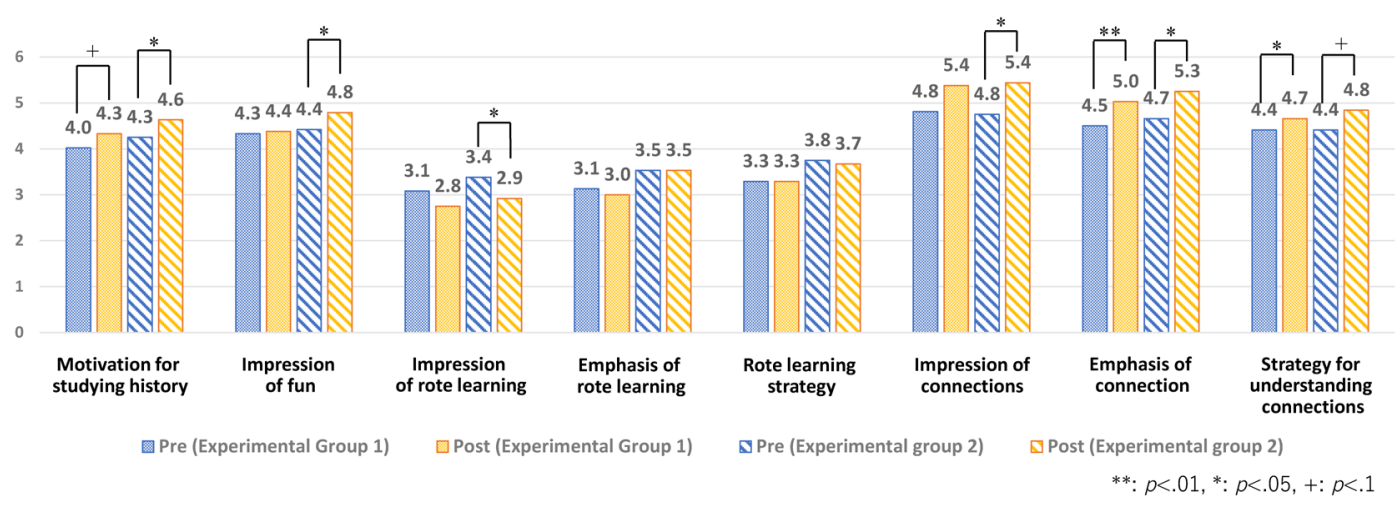

Figure 4. Results of historical learning awareness questionnaire

and (8) Strategy for understanding connections).

These results suggest that in the context of cultivating a learning attitude whereby students learn about the background of subjects by supporting historical interpretation activities, this learning attitude has possible beneficial effects of providing support with this system's history interpretation learning design and support features wherein historical cartoons are used as learning materials.

To investigate whether there was a statistical difference between the evaluation scores before and after using the system, a paired t-test with a significance level of $5 \%$ and effect size $r$ was calculated. In experimental group 1, significant differences were found at the $5 \%$ level for two items: (7) Emphasis on connection $(p=.008, r=.81)$, and (8) Strategy for understanding connections $(p=.033, r=.71)$. In experimental group 2 , significant differences were found at the $5 \%$ level for five items: (1) Motivation for studying history $(p=.017$, $r=.76$ ), (2) Impression of fun $(p=.038, r=.69)$, (3) Impression of rote learning $(p=.020, r=.75), \quad(6)$ Impression of connections $(p=.036, r=.70)$, and (7) Emphasis on connection $(p=.014, r=.78)$.

The Usefulness of Concept Maps. In the system used by experimental group 2, a total of 12 representation objects were set with gaze target information by the authors of the learning materials. Of these, eight learners in this group looked at eight objects on average.

The keywords used for web searching included many terms corresponding to the states or actions of representation objects shown in the cartoons, such as
"Sino-Japanese War and Fishing" and "Sino-Japanese War and Kimono." The total number of keywords (except for duplication) used for web search in experimental groups 1 and 2 were 22 and 30, respectively. Thus, compared with experimental group 1, it was found that experimental group 2 tended to use a more diverse range of search keywords.

Although both groups performed history interpretation activities using the same cartoons as their starting points, the abovementioned difference may have arisen because the function whereby the learners belonging to experimental group 2 are shown the displayed contents in the form of a concept map by looking at the cartoon directed more attention toward the content of the cartoon, thus helping to raise awareness among these learners of learning by using the cartoon as a starting point.

Usefulness of Presenting a Historical Viewpoint. An investigation was carried out to examine the average number of types of historical viewpoints set by each group, and it was found that there were 1.9 types in experimental group 1 and 2.9 types in experimental group 2.

In the system used by experimental group 1, even though no function was added for displaying historical viewpoints, the students were able to set historical viewpoints by themselves that could not be set in the preliminary history consideration task. This suggests that the cartoon learning materials contributed to encouraging interpretive activities by making learners proactive in setting a historical viewpoint. On the other hand, it is generally difficult for people to create new historical 
Table 4. Contents of descriptions reflected in the learners' reports after using the system (experimental group 2)

\begin{tabular}{c|l}
\hline Learner & \multicolumn{1}{|c}{ Contents of descriptions reflected in the learners' reports after using the system } \\
\hline A & $\begin{array}{l}\text { After winning this war with a large amount of reparation, Japan became more developed, powerful, and prosperous, } \\
\text { and firmly established its expansion to the south by annexing Taiwan. This may have been the origin of the Greater East } \\
\text { Asia War and the Greater East Asia Co-Prosperity Sphere. Perhaps Japan considered this as an opportunity to engage in } \\
\text { international warfare, resulting in the Russo-Japanese War, the Greater East Asia War, and World War II. }\end{array}$ \\
\hline B & $\begin{array}{l}\text { Japan as well as China under the rule of the Qing dynasty were still not fully modernized and were lagging behind } \\
\text { other countries, especially Russia. Therefore, Japan was planning to advance into the Asian continent in order to } \\
\text { expand its borders and develop economically. It was decided that taking control of Korea was an essential part of this } \\
\text { military strategy. In other words, Japan was planning to use Korea as a foothold in order to advance into the Asian con- } \\
\text { tinent. }\end{array}$ \\
\hline C & $\begin{array}{l}\text { Since it is connected with the Russo-Japanese War and both World Wars, it seems that this war could be one of the rea- } \\
\text { sons why Japan became the focus of so much attention from the international community. }\end{array}$ \\
\hline
\end{tabular}

Table 5. Correspondence between learner interpretations and answered questions

\begin{tabular}{l|l|l}
\hline \multicolumn{1}{c|}{ Description reflected in report } & \multicolumn{1}{c}{ Contributed question } & \multicolumn{1}{c}{ Learner A's response } \\
\hline $\begin{array}{l}\text { After winning this war with a large } \\
\text { amount of reparation, Japan became } \\
\text { more developed, powerful, and prosper- } \\
\text { ous, and firmly established its expansion } \\
\text { to the south by annexing Taiwan. }\end{array}$ & $\begin{array}{l}\text { Let's examine the popularity of topknot } \\
\text { hairstyles in Japan from an international } \\
\text { status viewpoint. }\end{array}$ & $\begin{array}{l}\text { It gives the impression that Japan was not } \\
\text { modernized. }\end{array}$ \\
\hline $\begin{array}{l}\text { This may have been the origin of the } \\
\text { Greater East Asia War and the Greater } \\
\text { East Asia Co-Prosperity Sphere. }\end{array}$ & $\begin{array}{l}\text { Try interpreting Japan's international } \\
\text { standing from the viewpoint of Japan's } \\
\text { opinions of other countries. }\end{array}$ & $\begin{array}{l}\text { Since Japan opened its borders, it has } \\
\text { aimed to improve its strength through } \\
\text { westernization, but this may have } \\
\text { resulted in it appearing rather backward } \\
\text { to Western countries. }\end{array}$ \\
\hline
\end{tabular}

viewpoints by themselves without any support from the system, and in the system used by experimental group 2, the presentation of historical viewpoints that are incorporated into the system beforehand was found to be useful for the students performing their own historical interpretation activities.

Historical Interpretations Developed Using the System. To investigate the historical interpretation activities performed by experimental group 2 with the support of the system, the contents of the learners' reports on the considered historical issues both before and after using the system were analyzed.

Table 4 shows some of the historical considerations that learners A, B, and C added after using the system. The criteria for choosing these three descriptions of three learners include their interpretation and explicit description of the background or speculation of history, as well as the impact of the considered historical event on subsequent events. In experimental group 1, although some described their interpretation of the events, none of them included such consideration about the events' significance and impact on subsequent eras.

It was observed that the learners constructed their own historical interpretations based on their feelings and the historical background, and established connections with and effects on subsequent events in history. This suggests that our system, which aims to provide adaptive support based on cartoon semantics, helps promote the learner's interpretation of history apart from rote learning.

Results of Analyzing the Usefulness of Question Presentation. To determine whether the questions that are dynamically created and displayed by the system based on cartoon semantics and question generation ontology helped to support history interpretation activities, the responses to the questionnaire item "Were the questions helpful for learning?" were examined with possible responses ranging from " 1 : Not at all" to "5: Yes, very much." The average score of 4.13 suggests that the presentation of questions in history learning activities was positively received by the learners and contributed to the transformation of their attitudes to 
history learning.

To confirm what sort of questions are useful in history interpretation activities, the authors of this study are currently analyzing which questions contributed to the descriptions reflected in the report after using the system. In this paper, the statements made by learner A are (stated in Table 5) considered as an example of such questions. Table 5 shows the contents of learner A's reflections in the report after using the system, the questions presented by the system that were considered to contribute to the description of the contents, and learner A's answers to these questions. Although this is just one example, it can be observed that the questions presented by the system contribute to history interpretation activities. The authors of this study plan to analyze other cases in future studies.

\section{Conclusion}

In this research, to accomplish the aim of motivating learners to study the background of topics related to historical events, the authors of this study developed a novel learning support system based on historical cartoon semantics that uses historical cartoons as learning materials and designed the learning activities by referring to three strategies that historians use when studying historical artworks. Subsequently, the authors of this study developed a system that supports historical interpretation activities whereby learners can perform self-exploratory learning in a step-by-step manner according to the historical interpretation process model, and wherein they are provided with support to encourage their historical interpretation activity according to their interests and learning situations. Consequently, it was confirmed that the system helps promote the learners' interpretation of history apart from rote learning and has the potential to change their learning attitude toward history.

Further work is needed to develop an authoring tool for expressing knowledge based on this cartoon semantic model.

\section{Acknowledgment}

This paper is an extended version of a paper presented in HCII 2020 (D. Muroya, K. Seta, and Y. Hayashi, "Learning support for historical interpretation using semantically enhanced historical cartoons", Lecture Notes in Computer Science, Vol. 12185. Springer. https://doi.org/10.1007/978-3-030-50017-7_14), and reprinted by permission from (C) Springer Nature.

\section{References}

[1] L. Levstik, "Negotiating the history landscape," Theory Res. Social Educ., vol. 24, no. 4, pp. 393-397, 1996.

[2] O. Hallden, G. Leinhardt, I. L. Beck, and C. Stainton, Teaching and Learning in History. Routledge, 2016.

[3] K. T. Spoehr, and L. W. Spoehr: "Learning to think historically," Educ. Psychol., vol. 29, no. 2, pp.71-77, 1994.

[4] T. Shindo, "Effects of metacognitive strategies on the meaningful learning: precondition to make the learning of history more interesting," (in Japanese), Res. J. Educ. Methods, vol. 28, pp. 95-105, 2003.

[5] A. V. Ciardiello, "Did you ask a good question today? Alternative cognitive and metacognitive strategies," $J$. Adolescent Adult Literacy, vol. 42, no. 3, pp.210-219, 1998.

[6] Y. Yoshikawa, "The formation and the development of 'questions' about history: On the cases of 'searching history' and 'leaning history'," (in Japanese), Bull. Fac. Educ., Yamaguchi Univ., vol. 60, pp. 337-350, 2010.

[7] D. Muroya, Y. Hayashi, and Seta, K., "Semantically enhanced gaze-aware historical cartoons to encourage historical interpretation," in Proc. of 25th Int. Conf. Comput. Educ. (ICCE2017), 2017, pp. 107-109.

[8] D. Muroya, Y. Hayashi, and K. Seta, "Historical cartoon semantics based learning support to enhance historical interpretation," in Proc. of 26th Int. Conf. Comput. Educ. (ICCE 2018), 2018, pp. 110-112.

[9] D. Muroya, K. Seta, and Y. Hayashi, "Learning support for historical interpretation using semantically enhanced historical cartoons," in Proc. of 22nd Int. Conf. Hum. Comput. Interact., 2020, pp. 206-218.

[10] S. Takahashi, B. T. Takahashi, A.Yoshikawa, and T. Terano: "A systematic approach to manga case method," in Proc. 23rd Int. Conf. Comput. Educ. (ICCE 2015), 2015, pp. 154-159.

[11] T. Miyahara and Chibaken rekishi kyoikusha kyogikai nihonshi bukai, Eds., Rekishi kyoiku ni okeru kaiga shiryo, Tokyo: Kokudosha (in Japanese), 1993.

[12] N. Ikeno, "A function of view of point on understanding history (1): On the analysis of understanding an illustration," (in Japanese), J. Jpn. Educ. Res. Assoc. Social Stud., vol. 40, pp. 23-32, 1992.

[13] A. Aoki, "A study of historical lessons using satire pictures in junior high school: The case of "TOBAE" by G. Bigot," (in Japanese), J. Res. Educ. Social Stud. Depart., 
vol. 18, pp. 39-46, 2006.

[14] https://hti.osu.edu/resources/cartoon-resources (accessed Dec. 3, 2020).

[15] H. Kuroda, Sugata To Shigusa No Tyuusei-shi, Tokyo: Heibonsha (in Japanese), 1986.

[16] C. Counsell, "Historical knowledge and historical skills: The distracting dichotomy," in Issues in History Teaching, J. Arthur and R. Phillips, Eds., London: Routledge, 2000, pp. 54-70.

[17] J. Jannet van Drie, C. van Boxtel, and J. van der Linden, "Historical reasoning in a computer-supported collaborative learning environment," in The Rutgers Invitation Symposium on Education series. Collaborative Learning, Reasoning, and Technology, A. M. O'Donnell, C. E. Hmelo-Silver, and G. Erkens, Eds., Mahwah, NJ: Lawrence Erlbaum Associates Publishers, 2013, pp. 265296.

[18] C. Jouault, K. Seta, and Y. Hayashi, "Content-dependent question generation using LOD for history learning in open learning space," New Generation Comput., vol. 34, no. 4, pp. 367-394, 2016.

[19] C. Jouault, K. Seta, and Y. Hayashi, "SOLS: An LOD based semantically enhanced open learning space supporting self-directed learning of history," IEICE Trans. Inf. Syst., vol. E100-D, no. 10, pp. 2556-2566, 2017.

[20] Halldén, O., "On reasoning in history", in Learning and Reasoning in History, J. F. Voss and M. Carretero, Eds., 1998, pp. 272-278.

[21] M. Kikuma, "Analysis of factors influencing high school students': Motivation to learn history," (in Japanese), Bull. Graduate School of Education of Waseda Univ., vol.17, no. 1, pp. 1-11, 2009.

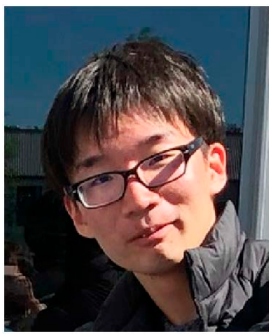

Daiki Muroya received the B.E. and M.E. degrees from Osaka Prefecture University in 2016 and 2018, respectively. He has been engaged in research on an ontology-based historical learning support system. He received the Best Poster Paper Award from ICCE in 2018. He currently works for Kobe Steel, Ltd.

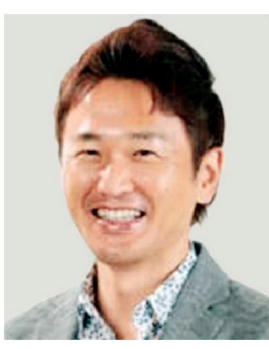

Kazuhisa Seta received his Ph.D. from Osaka University in 1998. He is currently a professor at the Graduate School of Humanities and Sustainable System Sciences, Osaka Prefecture University. His research interests include software engineering, intelligent tutoring systems, human-computer interaction, semantic web, and ontological engineering. He received SIG Awards from the Japanese Society of Artificial Intelligence in 2015 and 2017, SIG-Award from the Japanese Society for Information and Systems in Education 2017, Best Overall Paper Award from ICCE in 2017, and Best Paper Awards from the Japanese Society for Information and Systems in Education in 2012 and 2015, respectively. He is a member of the IEICE, JSAI, IPSJ, JSiSE, JCSS, APSCE, ACM, and IAIED.

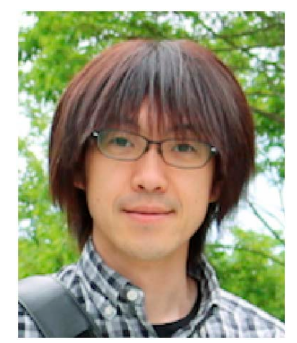

Yuki Hayashi received his Ph.D. degree in Information Science from Nagoya University in 2012. From 2009 to 2012, he was a recipient of the JSPS Research Fellowship for Young Scientists (DC1). From 2012 to 2014, he was an assistant professor at Seikei University. He is currently an assistant professor at the College of Sustainable System Sciences and the Graduate School of Humanities and Sustainable System Sciences, Osaka Prefecture University. His research interests include computer-supported collaborative learning and human-computer interaction. He received JSAI SIG Awards in 2015 and 2017, JSiSE SIG-Award in 2017, ICCE Best Overall Paper Award in 2017, and JSAI 30th Anniversary Best Paper Award in 2016. He is a member of the IPSJ, JSAI, JSiSE, HIS, and APSCE. 